\title{
International Co-operation in Astronomy
}

\begin{abstract}
M. MinnaerT
Sterrewacht, Utrecht, Netherlands

SumMary

Scientific co-operation between the nations is found already in Antiquity and the Middle Ages and has proved a strong stimulus to the development of astronomy. Different forms of modern international co-operation in astronomy may be distinguished: (1) co-ordinated observations at widely separated stations; (2) collective achievement of a great amount of work; (3) creation of international centres; (4) unification of notations and terminology. The increasing need for co-operation in astronomy was the reason for the constitution of international bodies, among which the I.A.U. acquired the greatest importance; the history of the Union shows that scientific co-operation must be kept outside political implications. International meetings, colloquia, travels, and exchanges should be encouraged. The introduction of an auxiliary international language would be highly desirable. International co-operation is a necessary complement to the national development of science.
\end{abstract}

\section{Early Forms of Co-operation}

From the earliest periods of civilization, contact between the nations has stimulated the development of science. In Antiquity, it was especially the interaction between the Oriental and the Greek world which had important consequences. Thales and Pythagoras, later Plato and Eudoxos, travelled to Egypt and were initiated into the wisdom of the priests. In 280 A.D. the Babylonian Berossos taught astronomy to Greek scientists at Kos. The transmission of astronomical learning from the Greeks to the Romans and the Arabs, later from the Arabs to Western Europe, was made possible by numerous laborious translations of astronomical textbooks, and it saved the continuity of the growth of astronomy.

At the end of the Middle Ages, the national groups were taking shape, and in each country centres of science developed with their particular schools of learning, influenced by exchanges and scientific relations. So, as early as in the thirteenth century, we find JoHn HoLYwoon, of York, as a professor of astronomy at the Paris University. And when the Renaissance stimulated all sciences and arts to a wonderful flowering, it was the international contact which diffused the new concepts, brought fresh ideas, and new impulses to a rejuvenating world. At most universities, students of many nations assembled, easily following the teaching in Latin. It became a custom that scientists in their youth should visit foreign countries in order to complete their education. Purbach travelled to France and Italy; Regiomontanus to Vienna, Rome and Hungary; Nicolaus of Cusa to the Netherlands, Germany, and Italy; Copernicus to Bologna, Rome, and Padua; Rheticus from N. Italy to Copernicus at Frauenburg; the young Tycho to Germany; Simon MaRius from Francony to Tycho and to Italy. Brilliant scientists were called as professors to foreign universities, in the same spirit of internationalism which is our pride nowadays. The printed book conveyed knowledge from one country to another and became the main instrument of international scientific co-operation: no other is so effective, so easy, so permanent.

However, the diffusion of new discoveries by books takes too much time and is not efficient for quick scientific intercourse. In hundreds of years, the real contact between actively working scientists was entertained by direct correspondence. The letters of HUYGENs, for example, comprise nearly one-half of his whole scientific 
production and have been published, together with the replies, in ten quarto volumes of about 600 pages each; they are addressed to scientists all over Europe. It was only in 1679 that the Connaissance des Temps appeared as the first important astronomical year book. From 1800 to 1813 the first astronomical periodical was edited by Baron von ZACH, the Monatliche Korrespondenz, followed after a short interruption by the Zeitschrift für Astronomie (1816-18) and the Correspondance Astronomique (1818-26); astronomers of several nations contributed papers and the editors endeavoured to give information about the development of astronomy all over the world. The important astronomical reviews which have originated since then have each kept their national character more or less, though papers of foreign colleagues are in general welcomed. This international contact has been considerably increased by the publication of regular observatory annals which are freely distributed to all foreign observatories, according to a system almost unique among scientists and testifying of the generosity of the great institutes in favour of the minor ones.

\section{Modern Co-operative Enterprises}

The aspects of international co-operation thus far described do not yet include the form which is considered nowadays as the most typical: an organization, consciously planned for team work. In 1736, when the French Academy of Sciences wished to compare an arc of the meridian at different latitudes, two expeditions were prepared, one to Lapony, the other to Ecuador; nobody considered the possibility of asking foreign countries to make independent observations which could be compared afterwards. Similarly, in 167I, the parallax of Mars was determined from the results of two French astronomers, Richer at Cayenne and Cassini at Paris.

Probably the first really co-operative international enterprise in astronomy was undertaken in 1761 and 1769 , when the transit of Venus was observed by numerous expeditions with a view to determining the solar parallax. The preliminary calculations were derived from an intercomparison of observations from a few distant stations; the final discussion, published by ENCKE in 1822 and 1824, was based on the individual results of all the stations. This then may be called the first type of worldwide astronomical co-operation: when observations are needed, made at distant stations, it is quite natural to combine the efforts of observatories of different nationalities. Such combined efforts for the determination of the solar parallax were repeatedly made later. For the Venus transits of 1874 and 1882 , the results were obtained independently by the French, by the German, by the English, and by the American observers, each from a comparison of their own national expeditions. Really international, however, was the co-operative observation of the minor planets Iris, Victoria, and Sappho, organized by GILL (1888-9); and so was the well-planned and fruitful Eros campaign of 1930-1, in which forty observatories co-operated. Of this same "first type" is also the International Latitude Service, created in 1898 and now centralized at Turin; it has become clear that this will have to be extended, since the number of co-operating observatories is not sufficient for the acquiring of complete information. Curiously enough, recent eclipse expeditions for the determination of longitudes by the observation of the beginning totality have nearly always been made by several parties of one and the same nation; it seems that international co-operation for this subject has not been considered as yet. Recent co-operative schemes are concerned with the continuous observation of solar phenomena: the sudden disturbances, especially the flares, are studied by a number of 
observatories, located at different geographical longitudes, each observatory being responsible for a daily one-hour watch. The progress of radiophysics has necessitated a similar organization for the observation of the radio noise-bursts and outbursts, though in this case a smaller number of stations is sufficient, because these phenomena are automatically recorded, independently of the weather. Three or four transmitting stations are broadcasting daily in code form a survey of the solar activity, the ionospheric perturbations, and the cosmic radiation in the last 24 hours ("ursigrams").

A second type of international co-operation has been organized in those cases where a scientific enterprise involves such a great amount of work that it could not be handled by one observer alone. Such collaboration is especially important for astronomy, which deals with an immense amount of material while depending on a limited number of scientists and instruments. Probably the earliest attempt in this direction was the conference convened by voN $Z_{A C H}$ at Lilienthal, in the autumn of 1800 , where twenty-four astronomers of different nations assumed the task of undertaking a systematic search for the hypothetical planet between Mars and Jupiter. To the same category belong: the project of the Catalogue of the Astronomische Gesellschaft, initiated by Argelander in 1867; the celebrated enterprise of the Carte du Ciel (Paris, 1887); and, more recently, the Plan of Selected Areas (1905). In the theoretical field, computational work is sometimes so extensive that even there a co-operation between the computing centres of different countries has proved very effective. For several tables of the astronomical almanacs the computations are carried out either in England, in Germany, in France, in Spain, in the U.S.A., or in the U.S.S.R. and the results are afterwards exchanged. Quite recently, the International Astronomical Union has planned a very interesting co-operative calculation of fundamental data concerning stellar atmospheres: the ionization, the absorption coefficient, and similar data will be computed at increasing depths for a great variety of model atmospheres, differing in their chemical composition; a dozen observatories have taken an interest in this work. The assistance of international computing centres with electronic machines will be of great value for similar problems in the future.

Mutual co-operation in industry leads to specialization and to distribution of the work. The same has proved true in astronomical research. The modern big telescopes produce photographic records at such a tremendous rate that it would be impossible for the astronomers of such an observatory to run their instruments continuously and to work out all these invaluable documents. It has become more and more frequent that colleagues of all nations receive the photographs which are necessary for their work or get the opportunity to take them themselves, while the measurements, the microphotometrical investigation of the plates and the theoretical development are made at their own institutes. Such a co-operation was inaugurated by KAPTEYN and GILL, when they agreed that the plates of the southern skies, obtained at the Cape Observatory (1885-90), would be measured at Groningen. The result was the Cape Photographic Durchmusterung. As one of the very numerous recent examples we may perhaps quote the Photometric Atlas of the Solar Spectrum, a result of a co-operation between the Mount Wilson and the Utrecht Observatories, and from which a Catalogue of Fraunhofer lines is being derived by another co-operation between some American and Dutch astronomers specialized in a particular branch of this subject.

A third type of co-operation has a more centralized character. The co-operation of a great number of observations is entrusted to a central bureau, which makes the 
combined results available to all. In about 1850 WoLF, at Zürich, had already begun his computation of sunspot relative numbers from observations made in many countries. We have now a centre for the observation of solar flares at Meudon; a centre for solar radio noise data at Sydney-Canberra; the Zuirich centre for the study of sunspot development and for the publication of a Quarterly Bulletin of Solar activity ; the Cincinnati, Heidelberg, and Leningrad centres for the ephemerides of minor planets; the Moscow Catalogue of Variable Stars. The same principle is applied to astronomical bibliography, embodied in the Astronomischer Jahresbericht at Heidelberg, the Bulletin Analytique, and the Science Abstracts, and also to the publication of the volume Observatoires et Astronomes, by the Uccle Observatory. An important institution of this kind is also the central Bureau for Astronomical Telegrams, which has been working at Copenhagen since 1922, and communicates by wire and by circulars the latest discoveries about novae, comets, or exceptional planetoids. The Bureau International de l'Heure, set up at Paris in 1913 and reorganized in 1919, intercompares the time determinations of several observatories and broadcasts time signals of high precision.

A far reaching plan for co-operative enterprise is the project of an international observatory, to be erected in the south of Europe, in excellent climatic conditions, and to be financed by those nations which desire to have the benefit of the telescopes there erected. This proposition was originally presented by the Polish delegation at the preparatory Copenhagen conference in 1947, and afterwards more fully developed by Professor Shapley, preference being given to a location in the southern hemisphere. It was put on a list of similar projects, submitted to the UNESCO, but relatively to these it was not considered to merit a high priority. In the meantime, a plan of the same character, though less ambitious, had been realized in Switzerland, where it became a decided success. The high altitude station at Jungfranjoch was organized there, not only for astronomical research, but also for the study of biological and cosmic ray problems; it receives contributions from several countries and is gradually developing its instrumental equipment in a most promising way. Very recently, a number of European observatories which had planned the establishment of small southern stations, have considered the possibility of building in common effort a first-class observatory in the southern hemisphere.

Compared to these ambitious enterprises, a fourth category of international cooperative work might look quite insignificant: the unification of notations, terminology, and units. However, all actively working astronomers know the confusions which arise if there is no general accord on such matters. Quite recently the definitions of time had to be again modified, a new unit of Fraunhofer line strength had to be introduced and a new terminology for radio-astronomy had to be found, these innovations being made necessary by new scientific advances. It was also important to reach agreement on the normals of wavelength to be used in spectroscopic work; or on the frequencies at which the solar radio noise will be observed, so that the measurements become comparable.

\section{Organizations for Internatonal Co-operation in Astronomy}

The increasing international co-operation in astronomical work made necessary the organization of congresses and the creation of a body where such co-operation could be systematically planned. One of the first astronomical meetings with an international character was the congress at Gotha in 1796. Because of the presence 
of the Frenchman LALANDE, the Austrian astronomers were not allowed by their government to take part at this meeting, and the court at Gotha was warned: "il pourrait bien s'agir d'autres révolutions que des révolutions célestes". 'The Duke and Duchess of Gotha did not care very much and were personally present. In 1863 the German astronomers founded the Astronomische Gesellschaft at Heidelberg, which from the start had a more or less international character, due to the membership of numerous foreigners. In 1904, systematic co-operation was started in the new field of astrophysics, when HALE succeeded in founding an International Union for Co-operation in Solar Research. The first meeting was held in St. Louis, in connection with the International Congress of Science. In a remarkable speech he emphasized that in co-operative scientific work special importance should be attached to the encouragement of individual initiative, no less than to the accomplishment of big projects for routine work.

The Union for Solar Research gave the inspiration for the constitution of a much more far-reaching and systematic organization of astronomical research. Immediately after the First World War, three meetings were held at London, Paris, and Brussels (1918-19), where an International Research Council was created, with several International Unions for the various sciences. Originally, the foundation of the Unions was not laid in a truly international spirit: interallied and neutral countries only were allowed to adhere. This may be frankly recognized: the Union has amply corrected this vitium originis, and ". . . 'tis thirty years since!" Already at the first meeting of the International Astronomical Union at Rome, in 1922, Professor Cerulli opened the general assembly by a speech in which he emphasized the necessity for uniting the astronomers of all nations, without any exception. After some years of hesitation, limitations to the membership were removed in 1926 and invitations for co-operation were addressed to Germany, Austria, and Hungary. But the seed of resentment bears evil fruits. It was only in 1947 that Hungary became a member, and it was 1952 when Germany and Austria joined. There could be no clearer demonstration that scientific co-operation must be kept outside all political implications, that it should never be used as a means of uniting one group of nations against another group. The I.A.U. has quickly developed a considerable and very stimulating activity. There are now thirty-three member countries. The work is distributed over forty-two Commissions, which act in a most efficient way and may truly be said to give inspiration to individual initiative, according to HALE's recommendation. The successive meetings of the Union, separated by intervals of three years, are each the result of intense scientific work and at the same time the starting point of new research. Besides these general meetings, small symposia for specialists on selected subjects have proved of great use.

In this whole organization, the General Secretary is the man carrying the heavy burden and the greatest responsibility; we shall never forget how Professor STRATton devoted more than ten years of his life to this important task and contributed more than anyone else to the vigorous development of the Union.

The international feeling has now become so strong among astronomers that very quickly after the Second World War scientific co-operation was resumed, and no new dissensions were allowed to disturb this work. It is a source of pride and happiness to the members of the Astronomical Union that among them the Russian, Polish, and Czech astronomers as well as the American colleagues give each other a fullhearted co-operation, that they regularly exchange their publications and fraternize 
at their meetings. A critical event was the preparation of the 1952 meeting, for which a Russian invitation had been received but finally was not accepted because of the international tension. Neutrality was saved, for the decision taken applied in the same way to meetings in the U.S.A. and in the U.S.S.R. But it is a sad thought that a more positive demonstration of the universality of science could not yet be realized.

International co-operation is more than the planning of a common scientific programme. It must never be forgotten that scientific research is made by men, and therefore it is not sufficient to exchange ideas-the scientists themselves should meet and discuss and work together. This is the reason why visits of astronomers to their colleagues abroad are so highly important and have developed to such an extent in recent years. It is a privilege when we are able to welcome great astronomers from distant parts of the world, to have them working, lecturing, discussing among us. But it is perhaps equally wonderful that young astronomers, in the springtime of their life, are able to visit foreign observatories, to enjoy the stimulus of fresh contact and new surroundings, to see excellent astronomers at work in their institutes and in the midst of their collaborators. Temporary assistantships for foreigners have become available at many observatories. If the financial means of an institute are limited, an exchange may be easily organized between a junior staff member and one of his colleagues at another institute, the salary of each of them being available for the maintenance of the visiting astronomer. The recent success of such arrangements is in a considerable degree due to the activity, practical spirit, and never-failing helpfulness of Professor Stratton, now the president of the I.A.U. Commission for Exchange of Astronomers.

In all international co-operation, the language differences are a major difficulty. At one time, Latin was the only vehicle of science and the common tongue of scientists all over the world. However, in the eighteenth and the beginning of the nineteenth century, when the influence of science on economic life and on society at large became increasingly important, the cryptic language of the learned was felt as an unendurable barrier between them and the nation. Temporarily, French was used in the learned societies all over Europe; then the vernacular superseded the Latin. But how about international relations? At first, French, German, and English were the languages of the great scientific periodicals and standard works. Gradually science developed in many other countries, which began to publish in Italian, Spanish, Japanese. Recently the remarkable rejuvenation of astronomy in Russia has put the problem before us in an acute form. While science is growing, it requires more and more labour to master the established disciplines and less time is left to learn foreign languages. There is thus an increasing need for reconsidering the whole problem, and radical solutions, such as the introduction of Esperanto as an auxiliary scientific language, should be seriously examined. Let the sceptical reader ask himself, whether he is able to propose a better solution.

In all its varied ways international co-operation in astronomy has developed quite naturally out of the requirements of scientific life itself. It has adapted itself to our modern way of living, it has become increasingly important, even to such an extent that it really could not be done without anymore. Let us for a moment ponder about the significance of this international contact as a complement to national differentiation. It is sound that science should develop within each country as a part of the national activity and in narrow connection with the local circumstances, the produc- 
tion, the special interests of the people. By the selection of the problems, by the philosophical background on which these are treated, by the special qualities of the nation, it will have a character of its own, even if it is an "exact" science like astronomy. The interaction of the work of all these nations automatically eliminates errors due to preconceived ideas; refinement of mind is complemented by stubborn labour or by practical common sense. But it is the faith of our life that ultimately there will never be contradictions between the findings of all these scientists, varied in their personalities and nationalities, since Nature is unique and since Truth is unique. And, finally, there emerges, in a purified form, what we may call International Science, which is no more the work of individuals but the work of the community, of humanity as a whole, the noblest expression of the human mind.

International scientific co-operation demonstrates to all that there is a way of living together on Earth in peace and mutual aid and happiness; a way of living which has not been found by politicians, but which has developed out of the simple desire for truth, and because we relied upon each other, and because we loved each other.

$$
\begin{aligned}
& \text {.. Ye Heavens, whose pure dark regions have no sign } \\
& \text { Of languor, though so calm, and though so great } \\
& \text { Are yet untroubled and unpassionate: } \\
& \text { Who though so noble share in the world's toil, } \\
& \text { And though so task'd keep free from dust and soil . . . }
\end{aligned}
$$

MatThew Arnold, 1852. ${ }^{1}$

\section{The International Astronomical Union}

P. Th. Oosterhofe

Sterrewacht Leiden, Netherlands

INTERNATIONAL co-operation in astronomy as well as international organization of certain specific problems which are too extensive or costly to be undertaken by a single observatory, have a long history. In the previous article Professor MinnaERT has given a general outline of the historical development of international co-operation in astronomical science. The same topic was treated by Professor Stratron when he delivered his Presidential Address at a meeting of the Royal Astronomical Society. ${ }^{2}$

Nevertheless it was not until 1919 that the many different and separate efforts were combined into a single organization. In common with some other Unions the International Astronomical Union was founded at the Constitutive Assembly of the International Research Council, which was held at Brussels in July 1919. During the thirty-four years which have elapsed since its establishment the Union has developed a great many activities in different fields and it has no doubt become an institution of unique value for astronomical science. Interesting facts about the early history of the I.A.U. can be found in an article by Dr. W. S. Adams (Publ. Astron. Soc. Pacific, 61, 5, 1949). 1 For full text see the fascinating collection "Dichters over Sterren" by M. MINNAERT (van Loghum slaterus, Arnhem,
$219 \mathrm{pp}, 1949$ ). - The Editor.

F. J. M. STRATTON; M.N. 94, 361-372, 1934. 